\title{
Movement of teeth and tissues reaction on movement
}

\author{
Alina Tykhomyrova* \\ Slavna Medical Clinic, Kyiv, Ukraine
}

\section{Introduction}

How is tooth movement during orthodontic treatment? It occurs by remodeling the bone. This process involves resorption and reorganization (apposition).

The movement takes place in response to the action of forces (Continuous, interrupted,intermitent). Continuous force on the crown of the tooth ltads tooth movement withing the alveolus, thats marked initially by narrowing of the periodontal membrane [1].

In the initial migration period ( hyalinisation phase, degeneration phase, reestablishment phase)

Hyalinization phase - after initial application of continuous force, compression in limited area of the membrane frequently impedes vascular circulation and cell differentiation causing degradation of cells and vascular vessels. In light microscopy we can see a glass-like tissue in this period [2].

Degradation phase - if the pressure is highest. In this period narrowing of membrane is most pronounced. Edvanced cellular and vascular changes may occur few hours. In Hyalinized zones cells can't differentiate into osteoclasts and no bone resorprion can take place.

Reestablishment - starts by synthesis of new tissue elements. Now membrane I wide and movement is beginning.

After applying force, there is pressure on the bone and soft tissue that surrounds the tooth. After a certain period of time (within 2030 hours in young humans/ Graber 260p) osteoclast is differentiated on the internal surface of the alveolus. The width of the periodontal membrane increases by the action of osteoclasts on the bone. There is a change in the orientation of fibrin fibers in periodontium.

\section{The second phase of displacement: after hyalinization phase}

The periodontal space is much expanded, the osteoclasts attack the surface of the bone where the pressure occurs (where the vector of force is directed), the tooth bone is reorganized by the production of new periodontal fibrils. The movement of the tooth is in the direction of pressure, where there is a process of resorption osteoclasts. At the same time, in the tension zone, there is a process of apposition of a alveolar bone through the proliferation of osteoblasts. After the process of cell proliferation has begun, osteoid tissue is deposited on the side of the tension $[3,4]$.

If there is excessive force application, the phase of hyalinisation occurs in the tissues (although this phase is inherent in any orthodontic movements of the tooth, but it is expressed differently and the duration is different). Excessive pressure causes collapse of the vessels, which reduces blood supply to tissues and a hyalineized zone that is a sterile necrotized area. In such areas, the cells can not differentiate into osteoclasts and resorb to bone to move, respectively, the movement may or may not occur, or occur, but very slowly. (Figure 1)

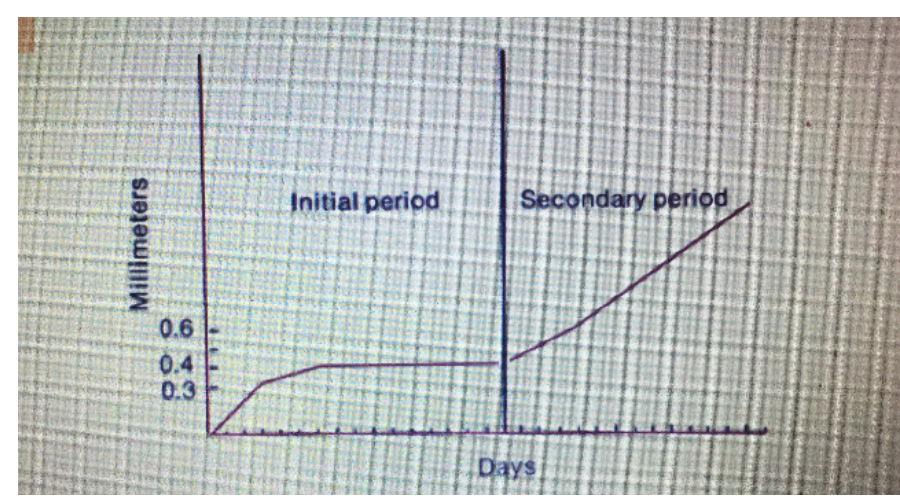

Figure 1. Degree of tooth movement before and after hyalinization. Tooth movement occurring after hyalinization is termed secondary period

The hyalinization zone is eventually eliminated by invasion of cells and vessels from the adjacent tooth. The gialized material is absorbed by phagocytic activity of macrophages. The restoration of attachment begins with the synthesis of new tissue elements. After cell proliferation has started, osteoid tissue is deposide on the tension side. New bone is deposide until the width of the periodontal membrane has returned to normal limits and fibrous system remodeled.

\section{Acknowledgment}

The material was prepared by Alina Tykhomyrova.

\section{References}

1. Xubair G. Tissue reactions in Orthodontic, Chapter 9. 260-267.

2. Reitan K (1964) Effects of force magnitude and direction of tooth movement on different alveolar bone types. Angle Orthod 244.

3. Raitan K (1960) Tissue behavior during orthodontic tooth movement. 46: 881-900.

4. Reitan K (1951) The initial tissue reaction incident to orthodontic tooth movement as related to influence of function. Acta Odontol Scand Suppl 6:1-240. [Crossref]

Copyright: (C2018 Tykhomyrova A. This is an open-access article distributed under the terms of the Creative Commons Attribution License, which permits unrestricted use, distribution, and reproduction in any medium, provided the original author and source are credited.

*Correspondence to: Alina Tykhomyrova, Slavna Medical Clinic, Kyiv, Ukraine, E-Mail: smailik@3g.ua

Received: July 16, 2018; Accepted: July 19, 2018; Published: July 21, 2018 